\title{
Investigating the impact of benefits and challenges of IOT adoption on supply chain performance and organizational performance: An empirical study in Malaysia
}

\author{
Khai Loon Lee ${ }^{a}$, Puteri Nurhazira Romzi ${ }^{a}$, Jalal Rajeh Hanaysha ${ }^{b}$, Haitham M. Alzoubi ${ }^{\text {b }}$ and Muhammad \\ Alshurideh ${ }^{\mathbf{c}, \mathbf{d}^{*}}$
}

${ }^{a}$ Faculty of Industrial Management, Universiti Malaysia Pahang, Malaysia

${ }^{b}$ School of Business, Skyline University College, Sharjah, United Arab Emirates

${ }^{c}$ Department of Management, College of Business Administration, University of Sharjah, United Arab Emirates

${ }^{d}$ Department of Marketing, School of Business, The University of Jordan. Amman, Jordan

\section{A B S T R A C T}

Article history:
Received September 19, 2021
Received in revised format
October 24, 2021
Accepted November 272021
Available online
November 302021
Keywords:
Internet of Things
Organizational performance
Supply chain performance
Malaysia manufacturing industry

\section{Introduction}

Industry 4.0 has been defined as the introduction of digitalization and the global transformation of the manufacturing industry. The term is usually discussed among industry people about how production floors currently operate based on a radical shift (Tjahjono, 2017). Autonomous robotics, horizontal and vertical system integration, simulation, the industrial internet of things, the cloud, cyber security, additive manufacturing, augmented reality, and big data and analytics are among the nine key technologies that form Industry 4.0. Everything in Industry 4.0, including field devices, machines, production modules, and products, is made up of Cyber-Physical Systems (CPS), as mentioned by (Ghazal et al., 2021; Ghazal et al., 2021; Hamadneh et al., 2021; Okano, 2017; Shamout et al., 2022). Everything will communicate with each other, trigger activities within each other, and control each other independently. Internet of Things (IoT) is one of the principal technologies that contribute to industry 4.0, where nowadays, it has become the most popular topic of discussion in various industries. According to Krotov et al. (2017), IoT can change the business processes, strategies and competencies across many industries through a new computing paradigm. In simple words, through the adoption of IoT, objects and machines can communicate with each other, identify, locate, sense, and control via the global platform (Vass et al., 2018). According to Okano (2017), IoT can be assumed as the worldwide and international network that helps and provides a range of capabilities of integrating

* Corresponding author

E-mail address: malshurideh@sharjah.ac.ae (M. Alshurideh)

(C) 2022 Growing Science Ltd. All rights reserved.

doi: $10.5267 /$ j.uscm.2021.11.009
In Malaysia, manufacturing industry is a major contributor to the economic advancement. As a result, cutting-edge technology like the internet of things (IoT) is projected to have a significant influence of IoT deployment on supply chains and organizational performance is relatively sparse. Therefore, this study is to determine the relationship between benefits and challenges of IoT supply chain performance in the relationship between IoT adoption benefits and challenges and organizational performance. The population of this study is comprised of 3019 manufacturing companies in Malaysia, while the minimum sample size needed is 43 manufacturing Equation Modelling (PLS-SEM) is used to assess all of the study's hypotheses. The results of this paper support six out of the seven hypotheses tested. In conclusion, the manufacturing industry in Malaysia needs to be exposed more to the benefits of IoT rather than keep discussing its challenges. This study can be a guideline to the manufacturing companies in decision making for IoT adoption.

(C) 2022 Growing Science Ltd. All rights reserved. responses received represte set of survey questionnaire were distributed through email and 63 
the physical world. Data gathering, processing, and analysis are all methods for integrating. IoT sensors, which are present in everything and will be interconnected through the public communication network, created the data analysis. The adoption and usage of IoT can help a company improve its capabilities. Based on the idea of organizational capabilities viewpoint, IoT can improve the ability to integrate suppliers, customers, and intra-organizational logistical operations (Al Kurdi et al., 2020; Alshurideh et al., 2012, 2015). Simply said, the Internet of Things (IoT) will connect the physical and digital worlds by synchronizing information flow with physical flow. As a result, a business may improve supply chain integration (Vass et al., 2018). Companies may substantially improve their productivity in terms of costing, customer happiness, and client retention by incorporating current technology into their enterprises (Aburayya et al., 2020; Al-Zu'bi et al., 2012; AlShamsi et al., 2021; Al Kurdi et al., 2020). A robust and efficient supply chain may help businesses achieve this. Business leaders, on the other hand, have more control over their operations because of technological advancements (Almaazmi et al., 2021; Alshurideh et al., 2021; Mehrez et al., 2021). It has made supply chains more transparent and simpler, allowing for easier access. Simply said, businesses that use digital technology have a significant competitive advantage over their competitors (Alshurideh et al., 2019; Nuseir et al., 2021; Lehtisalo, 2018).

\subsection{Contemporary issues}

Organizations and industries can become a more competitive advantage because of information technology (IT) advancements. With the help of IoT, manufacturers can deliver amenities through the product life cycle, improve their work, and reduce the risk of product-related discontinuation. (Haddud et al., 2017) stated that IoT could bring significant business benefits as the usage of IoT in the supply chain provides a potential for improving operational processes and reducing costs and risks. Even though the adoption of IoT can positively influence supply chain performance, there are still numerous challenges to be faced, especially in technical and social. Effective adoption and diffusion of IoT can be confirmed if those challenges are solved. Adoption or use of IoT helps the organization to build its competence. Identifying the pros and cons of adopting IoT to the supply chain can improve and upgrade performance. The positive supply chain performance will significantly impact organizational performance because it shows that the organization fully optimized the IoT. According to Hasselblatt et al. (2018), based on strategy and reports for the European industry in 2020, increasing usage of digital and IoT will increase the yearly returns by 110 billion Euros. It shows that technologies and digitization are important for future industrial development. The problem that leads to conducting this study is issued by Haddud et al. (2017), where there is a lack of research on IoT's use in supply chains and how it affects organizational performance. Unfortunately, none of the previous studies had carried out the analysis of benefits and challenges adoption of IoT towards organizational performance by analyzing the data from the manufacturing industry's perception. Therefore, manufacturing employees lack exposure to IoT technology. This study determines the effects of the benefits and challenges of IoT adoption on organizational performance. Furthermore, this study looks at the role of supply chain performance in mediating the relation between the advantages and challenges of IoT adoption and organization performance.

\section{Literature review}

The Internet of Things (IoT), often known as the Internet of Everything or the Industrial Internet, is a new technological paradigm that allows machines and gadgets to communicate in a worldwide network. As for Ghazal et al. (2021) and Tang et al. (2018), IoT develops trends, provides a good planning strategy and is known as innovative technology, and IoT is not the only buzz word for the company. Due to its capability, IoT is known as one of the important areas for upcoming technology, and many industries pay attention. According to Lee and Lee (2015), five key IoT technologies are extensively utilized in IoT-based services and products: wireless sensor networks (WSN), radio frequency identification (RFID), cloud computing, middleware, and IoT application software. Using radio waves to automatically recognize people or objects from a distance of several inches to hundreds of feet is the first technology IoT, RFID. RFID technology helps to improve system efficiency because it uses an automatic data capture system. Compared to traditional identification devices like barcodes, the tags of RFID can store more data. The RFID tag can be attached to any physical object such as cash, clothing and possessions because the tags can survive in a harsh environment and are not easily damaged. This technology is being utilized by many industries, including logistics, pharmaceutical, production, and retail. WSN is a technology of IoT that consists of autonomic sensors that monitor physical or environmental environments. It can work using systems of RFID in detecting the location, temperature, and movements of things. Cold chain logistics, maintenance, and tracking systems are the areas that commonly use WSN. Besides, Middleware is an interrupted software layer between application and technology levels. The vital role of Middleware is to simplify the mixing of inheritance technologies into new ones. Furthermore, cloud computing is a computing paradigm that enables on-demand access where it allows pool users to share configured source computing. Examples of it are computers, networks, servers, storage, applications, services, and software (Al Kurdi et al., 2021; Alshurideh et al., 2019; Hanaysha et al., 2021). The objective of cloud computing is to provide dynamically-scale infrastructure for applications, data storage and files. In comparison, IoT applications software allow interaction between devices, and human-to-device communications modes are dependable and stable (Lee \& Lee, 2015). It is forecasted that supply chain partners will be affected regarding the availability of information and supply chain operations. IoT is widely utilized in a variety of industries, including manufacturing, health care, financial and insurance services, retail, energy, and materials (Tang et al., 2018). The ultimate objective of IoT, according to (Alzoubi et al., 2021; Tu, 2018), is to create a worldwide system architecture to ease the interchange of products, services, and information. Some companies applied the IoT or IIoT to engage in real-time information gathering, where the technology manages to improve efficient operations. 
Companies in the field related to logistics are gaining a lot of benefits through the innovation of IoT, where the operation of enterprises keeps improving. According to Tang et al. (2018), IoT's growth has tripled in the last five years. Financial returns are the key to IoT to be fully adopted where the company expects IoT to be one of the sources of revenue (Tang et al., 2018). In recent years, overall IoT hardware spending, such as RFID tags, has significantly decreased. But still, many companies are hesitant towards the IoT ( Tu, 2018). In this study, the measurement for benefits adoption of IoT includes supply chain efficiency and visibility of supply chain while the measurement for challenges adoption of IoT is uncertainties in the trustworthiness of technology and organization adjustment.

\subsection{Supply chain performance}

In the supply chain, the resources collection process is required to create and deliver the products to the end customers (AlSuwaidi et al., 2021; Alzoubi \& Yanamandra, 2020; Hayajneh et al., 2021; Rajgopal, 2016). According to Kaliani Sundram et al. (2016), there is a systematic method for assessing the efficacy and efficiency of supply chain activities (Ali et al., 2022). However, the efficiency and effectiveness of the action eligibility process are known as performance measures. Performance measurement gives decision-makers the information they need for management feedback. Performance measurement equips decision-makers with the data they need to offer management feedback (Sillanpää, 2010). Supply chain management is challenging to measure because each individual's supply chain management carries a different meaning. Thus, the approach has so many variations (Ali et al., 2021). But it is still important to measure the supply chain's performance because of the need to provide information to the top management (Sillanpää, 2010). The measurement for supply chain performance in this study refers to supply chain flexibility, resources, and output.

\subsection{Organizational performance}

Organizations play an important role in supply chain operation where the success of an organization will represent the nation's development. It is very common in academic literature to discuss the concept of organizational performance, but its accurate definition is still difficult to confirm since it has many meanings (Alnuaimi et al., 2021; Gavrea et al., 2011). To survive and succeed in modern business, it is essential to compete in a market where customers, inputs, and capital is indicators of organizational performance (Alaali et al., 2021; Alzoubi \& Aziz, 2021). Departments in the company such as marketing, operations, human resources, and strategy will be judged according to their contribution, also known as one of the methods to measure an organization's performance (AlShehhi et al., 2021; Alzoubi et al., 2021). The organization is only able to improve performance when the performance is measurable (Richard et al., 2009). Financial performance, product market performance, and shareholder return are three aspects of company outcomes that strategic management drives via organisational performance (Richard et al., 2009). A balanced scorecard, benchmarking, business process reengineering, and comprehensive quality management are just a few examples of ways to assess organisational performance (Alzoubi \& Ahmed, 2019; Tadejko, 2015).

\subsection{Hypotheses development}

In supply chain management, IoT has hopes and concerns in improving business performance. From the perspective of supply chain management, when several problems arise, IoT allows a machine to decide with least or no human intervention. IoT integrates and enables information communication technology, including RFID, wireless sensor network, machine-tomachine system, and mobile application (Haddud et al., 2017; Zhou et al., 2015). Before applying IoT in the supply chain management system, problems in the actual situation, over stocking and late delivery are common due to complexity and uncertainty. Hence, by implementing IoT, the supply chain management system becomes more competent to overcome the drawbacks of past experiences (Abdel-Basset et al., 2018). Table 1 shows the characteristics of supply chain management that apply to IoT.

\section{Table 1}

Characteristics of SCM that apply IoT

\begin{tabular}{ll}
\hline Characteristics & Explanation \\
\hline Instrumented & The machine will generate all the information in the supply chain. \\
Connected & Things are interconnected via using smart objects and an IT system. \\
Intelligent & Making a larger scale of optimal decisions through optimize performance. \\
Automated & Automated processes are used to substitute low-efficiency resources. \\
Integrated & All stages in the supply chain are collaborating with each other. \\
Innovative & Development of new value through solutions for fulfil new requirements. \\
\hline Source: Adapted from (Abdel-Basset et al., 2018)
\end{tabular}

As stated by Haddud et al. (2017), in the new business environment, the supply chain must react and amend itself to the fast growth of IoT to achieve more significant benefits and more competitive advantages. The benefits of IoT on the supply chain are enhanced inventory management, real-time supply chain management, and maximize transparency of logistics. By using IoT, real-time visibility of the inventory has been generated where it improves the management of inventory. Therefore, the inventory management process will not rely on guesses anymore and prevent inventory disorder issues caused by manual 
data collection. The rate of inventory is $100 \%$ accurate with the addition of sensors in the inventory process. A conventional supply chain distributes demand information to only one partner rather than sharing it. The latest RFID tag technologies may be used to perform real-time supply chain management. It allows you to keep track of various sorts of process data, such as expiration dates, manufacturing dates, and warranty periods. The supply chain will be efficiently managed because of this. All transportation information, such as the state of the conveyance, the destination, and so on, will be accessible to the whole supply chain via smart objects. As a result, logistical transparency may be established. On the other hand, the possibility of monitoring and conserving products will rise, which will assist to reduce the cost of returns and have a significant influence on customer satisfaction. (Abdel-Basset et al., 2018). Other than reaping the benefits of IoT adoption, there will be other challenges and impediments to overcome. Many organisations decide not to embrace IoT because management still does not grasp the potential benefits that might be achieved through IoT adoption, as Haddud et al. (2017) points out. Another major impediment to IoT deployment is the difficulty of finding people with the necessary expertise and skills to manage the technology (Lee \& Lee, 2015). Incorporating new technology into the existing corporate environment, structures, and models is the most difficult element of the job (Haddud et al., 2017). As a result, two hypotheses are suggested to explain the relationship between benefits and challenges of IoT adoption and organizational performance.

\section{$\mathbf{H}_{1}$ : Benefits of IoT adoption positively affects organizational performance. \\ $\mathbf{H}_{2}$ : Challenges of IoT adoption positively affects organizational performance.}

Nowadays, competition among companies is extreme, which comes from the pressures of the fast-changing technology with the global challenges. The force of technological changes and global challenges portrays the manufacturing industry needs to act fast in transferring the materials, more complex payment system, and the densification of products' life cycles. Thus, superior technology integration is required to fulfil increased sophisticated customers' demands (Caputo et al., 2016). A company's success is not being determined by their response to their customers or their organization's needs, but they also need to expect the future of the trend. Due to frequent technological pressure, the emergence of the internet has profoundly affected a company's approach to production. Thus, organizational and operational structures have been strongly reshaped (Caputo et al., 2016). The primary use of IoT technology is to comprehend intelligent insight and accessing various manufacturing resources and capabilities. Thus, based on academic research, industrial organizations have increased investment in new IoT technologies. IoT technology will monitor processes, optimize operating hours, detect errors, and have optimum control (Yang et al., 2019). One of the main factors that affect the company's survival is innovation, where adopting IoT can be said as one of the innovations made by the company in terms of technology. Even though IoT is recognized as one of the innovations that companies can approach, there are still challenges to adopting it. According to Lee and Lee (2015), the challenges in IoT development are: challenge in managing the data, in mining the data, lack of privacy and security. Despite all the challenges faced in adopting the IoT, it is worthwhile for companies to achieve a competitive advantage globally. Modern manufacturing companies struggle to create new products or services with extraordinary features as survival skills in the harsh environment of business (Yang et al., 2019). Therefore, five hypotheses that lie under the relationship between IoT, supply chain performance and organizational performance are proposed:

H3: Benefits of IoT adoption positively affects supply chain performance.

$\mathbf{H}_{4}$ : Challenges of IoT adoption positively affects supply chain performance.

H5: Supply chain performance positively affects organizational performance.

$\mathbf{H}_{6}$ : Supply chain performance mediates the relationship between benefits of IoT adoption and organizational performance.

$\mathbf{H}_{7}$ : Supply chain performance mediates the relationship between challenges of IoT adoption and organizational performance.

Based on the discussion mentioned above, the conceptual framework of this study is illustrated in Fig. 1.

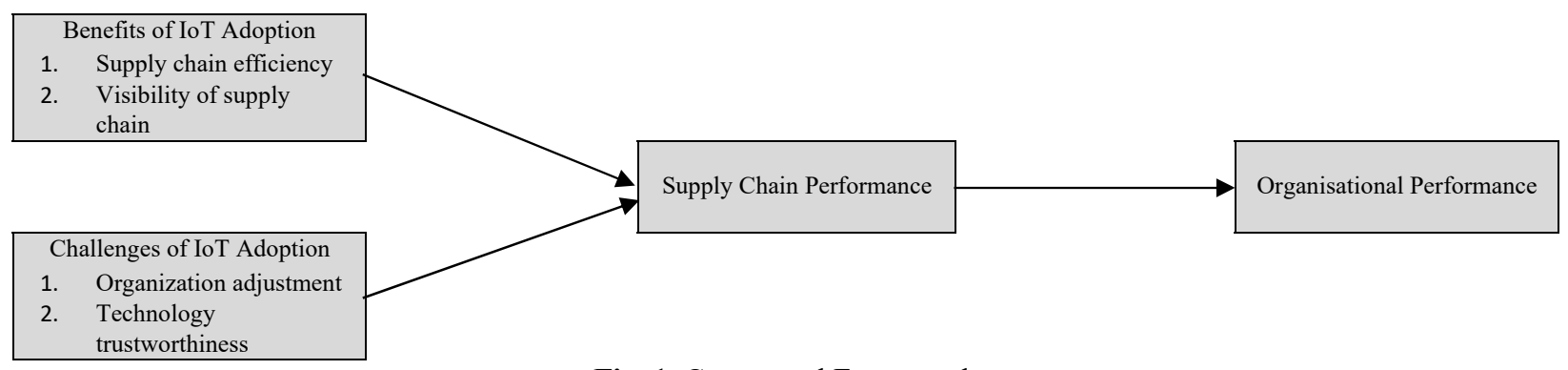

\section{Methodology}

Fig. 1. Conceptual Framework

A quantitative research design is applied to achieve the research objectives and test the hypotheses in this study. Based on the Federation Manufacturer Malaysia (FMM) directory, there are 3019 manufacturing companies listed in Malaysia. $\mathrm{G} \times$ Power software is used to get the minimum sample size for this study. Based on the calculation in $\mathrm{G} \times$ Power, at least 77 
samples are required for this study. The survey questionnaire is targeted at the manager or executive involved in the supply chain in the company. Managers and executives are chosen because managers and executives have more knowledge and experience in operation. In quantitative research design, a survey questionnaire will be an instrument for this study to collect data. The survey questionnaire consists of five sections: part A contains the respondent's profile, and parts B to E contains the measurement items for the variables under study. The respondents can choose one answer from the five points Likert scale that best represents their idea on the particular question. The questionnaire then has been constructed using an online platform, Google form, to ease the respondents in answering the questionnaire. The researchers email a set of structured and closed-ended survey questionnaires to the respondents (Showkat \& Parveen, 2017). Partial least square structural equation modelling (PLS-SEM) with the support of SmartPLS software is applied to assess the measurement and structural model of this study (Hair et al., 2011; Hair et al., 2014). Large quantities of raw data are transformed into tables, charts, frequency distributions, and percentages in descriptive analysis. Mean, frequency, standard deviation, and percentage will be provided in tables and graphs for data analysis in this study. The purpose of it is for a clear understanding of the result obtained (Loeb et al., 2017). Besides, descriptive analysis has also been used to represent each construct's means in the measurement model. Specifically, reliability is used to ensure that the research is suitable in any population or even applicable in the future. Convergent validity, on the other hand, can explain the item's variance by utilizing a construct that converges in its indicator. Convergent validity will be estimated using outer loading, average variance extracted (AVE), and composite reliability (CR). According to (Hair et al., 2014), acceptable values for outer loading must be above 0.70, while acceptable values for AVE must be 0.50 or above, since this value or higher implies that the construct will explain more than $50 \%$ of the variation of its components on average. For an appropriate model for confirmatory purposes, the acceptable cut-off for composite reliability is equal to or greater than 0.70 (Alhamad et al., 2021; Garson, 2016; Henseler et al., 2012). Discriminant validity will be determined after convergent validity has been measured. The degree to which a construct is empirically different from other constructs is referred to as discriminant validity. The HTMT (Heterotrait-Monotrait) criteria is a method for determining discriminant validity. According to Garson (2016) and Jörg Henseler et al. (2012), the proposed HTMT value for discriminant validity between a pair of reflective constructs must be less than 0.90 . In addition, bootstrapping is used for hypothesis testing, where it computes significance for R-square, AVE, CR, and the Heterotrait-Monotrait ratio (HTMT) (Garson, 2016). The results of hypotheses testing will be presented in t-value and p-value.

\section{Results and findings}

\subsection{Descriptive analysis}

A total of 1160 sets of the questionnaire had been distributed by email to manufacturing companies. The researchers received 80 responses from the respondents that represented 6.89 per cent of the response rate. In this research, descriptive analysis is used to determine elements in benefits and challenges adoption of IoT, supply chain performance and organizational performance focused on by manufacturing companies. The descriptive statistics of the variable are presented in Table 4.1. Based on the result, the mean value for BIoT (benefits adoption of IoT) is 3.708, while the mean value for CIoT (challenges adoption of IoT) is 3.621. The mean value for SCP (supply chain performance) is 3.834. Meanwhile, the mean for OP (organizational performance) is 3.761. While the standard deviations of all the variables are all above 0.93.

Table 1

Descriptive Analysis

\begin{tabular}{llll}
\hline Variable & N & Mean & Standard Deviation \\
\hline BIoT & 80 & 3.708 & 0.997 \\
CIoT & 80 & 3.621 & 0.939 \\
SCP & 80 & 3.834 & 0.995 \\
OP & 80 & 3.761 & 0.962 \\
\hline
\end{tabular}

\subsection{Measurement model assessment}

The data in this study was analyzed using partial least square structural equation modelling (PLS-SEM) by the researchers (Lowry \& Gaskin, 2014). In this study, two forms of validity were used to evaluate the measurement model: convergent validity and discriminant validity. Fig. 2. depicts the research model for this investigation. The advantages and barriers of IoT adoption are independent factors in the study model, while organizational performance is the dependent variable, with supply chain performance serving as a mediating variable.

\subsubsection{Internal consistency}

For the measurement model to achieve the acceptable value for variable indicator, the value of factor loading that is less than 0.40 should be deleted (Anderson, Hair, Black, 2010). Some of the measurement items need to be deleted in the model to achieve dimensionality among the measurement items. Therefore, three items with low factor loading have been deleted, including the item of B8, C4, and C8. Hence, the remaining measurement items in Table 2 support convergent validity for all four constructs. All remaining loadings are now greater than 0.40 , with most loadings exceeding 0.70 . 


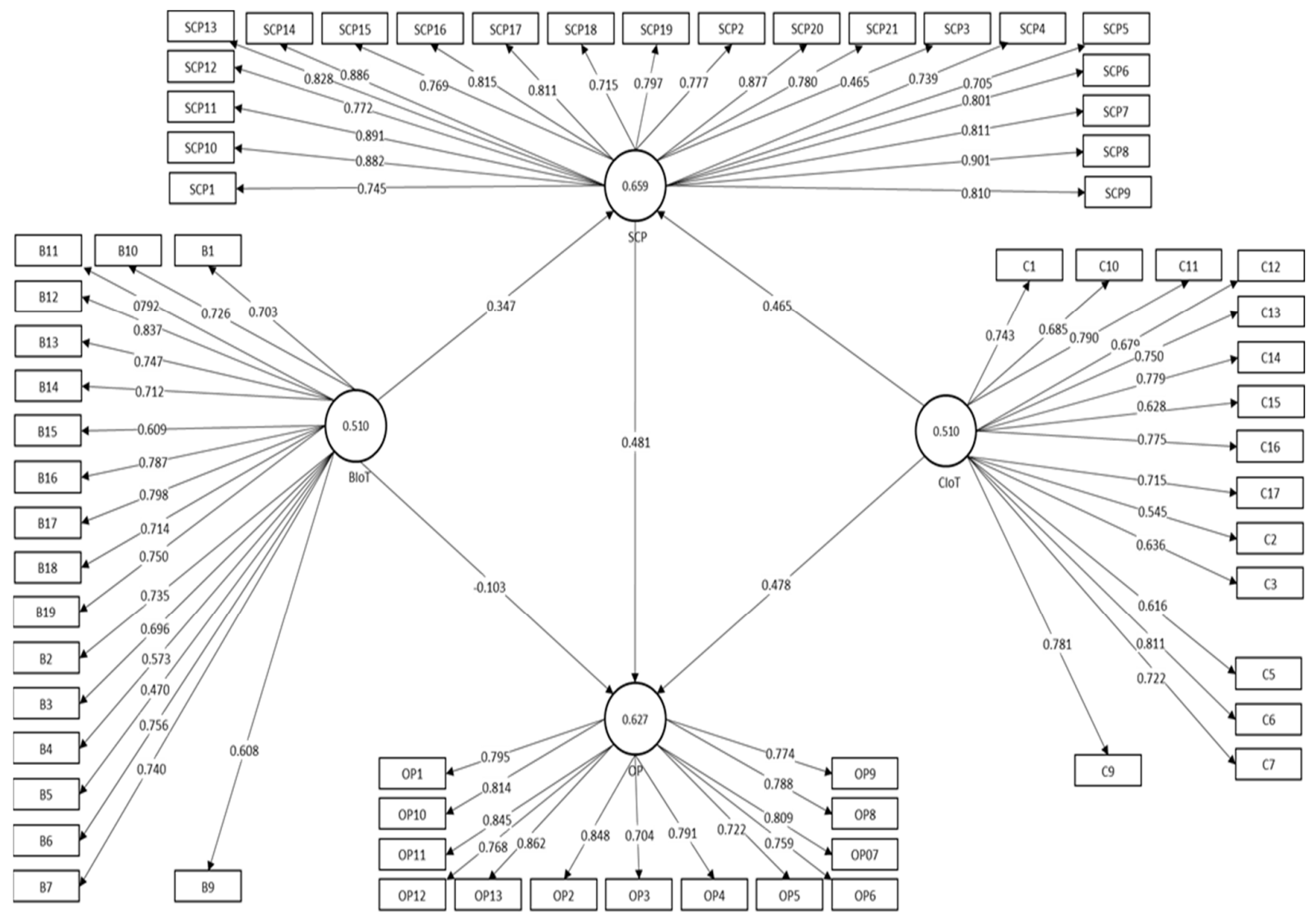

Note. Deleted items B8, C4, and C8

Fig. 2. Modified PLS Path Model

\subsubsection{Convergent validity}

The researchers consider average variance extracted (AVE) and composite reliability (CR) when assessing the convergent validity. Convergent validity is a measurement model that the item's variance should be correlated with and predict values of the construct convergence in its indicators. AVE should be more than 0.5 where 50 per cent of the indicator variance is included in the construct score (Hair et al., 2017). According to Bagozzi (2006), the AVE value should be greater than 0.50 to achieve a satisfactory model. In addition, the accepted value for CR is equal to or more than 0.70 for confirmatory study while the value of CR is equal to or greater than 0.80 it is considered as good for confirmatory research (Alshurideh et al., 2020; Garson, 2016). Based on Table 2, the value of AVE fell between 0.510 to 0.659 where it exceeds the suggested value of 0.50 . Besides, the value of CR for each construct is between 0.939 and 0.976 which exceeds 0.7 and that means that all constructs show internal consistency reliability. According to Garson (2016) and Hanaysha et al. (2021), if the value of CR is greater than 0.9 , it may indicate that the multiple indicators are minor wording variants from each other rather than being truly representative measures of the construct the factor represents. Table 2 shows the results of measurement model assessments.

\subsubsection{Discriminant validity}

The purpose of establishing discriminant validity is to show that each construct captures a unique phenomenon not represented by any other construct in the model (Hair et al., 2017). In this study, Heterotrait-monotrait (HTMT) has been selected instead of cross-loadings and Fornell-Larcker criterion to present the discriminant validity. As suggested by Henseler et al. (2015), discriminant validity is established between a given pair of reflective constructs if and only when the HTMT value is below 0.90 . Table 3 shows that all the constructs have fulfilled the requirements of discriminant validity. 
Table 2

Results of Measurement Model Assessments

\begin{tabular}{|c|c|c|c|c|c|}
\hline Construct & Total No of Items & Remain items & Factor Loading* & Composite Reliability (CR) & Average Variance Extracted (AVE) \\
\hline \multirow[t]{18}{*}{ BIoT } & \multirow[t]{18}{*}{19} & $\mathrm{~B} 1$ & 0.703 & \multirow[t]{18}{*}{0.949} & \multirow[t]{18}{*}{0.510} \\
\hline & & $\mathrm{B} 10$ & 0.726 & & \\
\hline & & B11 & 0.792 & & \\
\hline & & B12 & 0.837 & & \\
\hline & & B13 & 0.747 & & \\
\hline & & B14 & 0.712 & & \\
\hline & & $\mathrm{B} 15$ & 0.609 & & \\
\hline & & B16 & 0.787 & & \\
\hline & & $\mathrm{B} 17$ & 0.798 & & \\
\hline & & B18 & 0.714 & & \\
\hline & & B18 & 0.750 & & \\
\hline & & B2 & 0.735 & & \\
\hline & & B3 & 0.696 & & \\
\hline & & B4 & 0.575 & & \\
\hline & & B5 & 0.470 & & \\
\hline & & B6 & 0.756 & & \\
\hline & & B7 & 0.740 & & \\
\hline & & B9 & 0.608 & & \\
\hline \multirow[t]{15}{*}{ CIoT } & \multirow[t]{15}{*}{17} & $\mathrm{C} 1$ & 0.743 & \multirow[t]{15}{*}{0.939} & \multirow[t]{15}{*}{0.510} \\
\hline & & $\mathrm{C} 10$ & 0.685 & & \\
\hline & & $\mathrm{C} 11$ & 0.790 & & \\
\hline & & $\mathrm{C} 12$ & 0.679 & & \\
\hline & & $\mathrm{C} 13$ & 0.750 & & \\
\hline & & $\mathrm{C} 14$ & 0.779 & & \\
\hline & & $\mathrm{C} 15$ & 0.628 & & \\
\hline & & $\mathrm{C} 16$ & 0.775 & & \\
\hline & & $\mathrm{C} 17$ & 0.715 & & \\
\hline & & $\mathrm{C} 2$ & 0.545 & & \\
\hline & & $\mathrm{C} 3$ & 0.636 & & \\
\hline & & C5 & 0.616 & & \\
\hline & & C6 & 0.811 & & \\
\hline & & $\mathrm{C} 7$ & 0.722 & & \\
\hline & & $\mathrm{C} 9$ & 0.781 & & \\
\hline \multirow[t]{21}{*}{ SCP } & \multirow[t]{21}{*}{21} & SCP1 & 0.745 & \multirow[t]{21}{*}{0.976} & \multirow[t]{21}{*}{0.659} \\
\hline & & SCP10 & 0.882 & & \\
\hline & & SCP11 & 0.891 & & \\
\hline & & SCP12 & 0.772 & & \\
\hline & & SCP13 & 0.828 & & \\
\hline & & SCP14 & 0.886 & & \\
\hline & & SCP15 & 0.769 & & \\
\hline & & SCP16 & 0.815 & & \\
\hline & & SCP17 & 0.811 & & \\
\hline & & SCP18 & 0.715 & & \\
\hline & & SCP19 & 0.797 & & \\
\hline & & SCP2 & 0.777 & & \\
\hline & & SCP20 & 0.877 & & \\
\hline & & SCP21 & 0.780 & & \\
\hline & & $\mathrm{SCP} 3$ & 0.739 & & \\
\hline & & SCP4 & 0.705 & & \\
\hline & & SCP5 & 0.801 & & \\
\hline & & SCP6 & 0.811 & & \\
\hline & & SCP7 & 0.888 & & \\
\hline & & SCP8 & 0.901 & & \\
\hline & & SCP9 & 0.810 & & \\
\hline OP & 10 & OP1 & 0.795 & 0.956 & 0.627 \\
\hline & & OP10 & 0.814 & & \\
\hline & & OP11 & 0.845 & & \\
\hline & & OP12 & 0.768 & & \\
\hline & & OP13 & 0.862 & & \\
\hline & & OP2 & 0.848 & & \\
\hline & & OP3 & 0.704 & & \\
\hline & & OP4 & 0.791 & & \\
\hline & & OP5 & 0.722 & & \\
\hline & & OP6 & 0.759 & & \\
\hline & & OP7 & 0.809 & & \\
\hline & & OP8 & 0.788 & & \\
\hline & & OP9 & 0.774 & & \\
\hline
\end{tabular}

Note. BIoT (Benefits adoption of IoT), CIoT (Challenges adoption of IoT), SCP (Supply Chain Performance), OP (Organisational Performance), * Factor loadings for 
Table 3

Heterotrait-Monotrait (HTMT)

\begin{tabular}{|c|c|c|c|c|}
\hline & BIot & CIoT & $\mathrm{OP}$ & SCP \\
\hline \multicolumn{5}{|l|}{ BIoT } \\
\hline CIoT & 0.859 & & & \\
\hline OP & 0.657 & 0.777 & & \\
\hline SCP & 0.718 & 0.766 & 0.745 & \\
\hline
\end{tabular}

\subsection{Structural model assessments}

\subsubsection{Hypotheses testing}

Seven hypotheses are being investigated in this study. In SmartPLS 3, PLS Bootstrapping is utilized to evaluate all hypotheses. The hypotheses were tested using a one-tailed t-test with a significance threshold of 0.05 . To obtain the level of acceptability, the t-value on the one-tailed test of statistical significance must be more than 1.645 and the p-value must be less than 0.05 . The results of the hypothesis testing are shown in Table 4 . The first hypothesis, H1, forecast benefits adoption of IoT (BIoT) and positively affects organization performance (OP). The results show that it is statically insignificant at tvalue 0.623 and p-value 0.267 . The second hypothesis, $\mathrm{H} 2$, forecast challenges adoption of IoT (CIoT), positively affecting $\mathrm{OP}$, shows a statistically significant result at $\mathrm{t}$-value 3.442 and $\mathrm{p}$-value 0.000 . The third hypothesis, $\mathrm{H} 3$ is supported at $\mathrm{t}$-value 2.539 and p-value 0.006 , in which BIoT is positively affecting supply chain performance (SCP). The fourth hypothesis is also supported at t-value 3.338 and p-value 0.000 , in which CIoT is positively affecting SCP. The fifth hypothesis is also supported at t-value 3.115 and p-value 0.001 , in which SCP positively affects OP. Therefore, four hypotheses (i.e. H2, H3, $\mathrm{H} 4, \mathrm{H} 5)$ are supported and one hypothesis (i.e. H1) is not supported.

Table 4

Result of Hypotheses Testing

\begin{tabular}{|c|c|c|c|c|c|c|c|c|c|}
\hline \multirow[t]{2}{*}{ Hypotheses } & \multirow[t]{2}{*}{ Path } & \multirow[t]{2}{*}{ Std Beta } & \multirow[t]{2}{*}{ SE } & \multirow[t]{2}{*}{ t-value } & \multirow{2}{*}{ p-value } & \multirow[t]{2}{*}{$\mathbf{F}^{2}$} & \multicolumn{2}{|c|}{$\begin{array}{c}\text { Confidence } \\
\text { Interval }\end{array}$} & \multirow[t]{2}{*}{ Decision } \\
\hline & & & & & & & 0.05 & 0.95 & \\
\hline H1 & $\mathrm{BIoT} \rightarrow \mathrm{OP}$ & 0.166 & -0.103 & 0.623 & 0.267 & 0.010 & -0.395 & 0.140 & Not Supported \\
\hline $\mathrm{H} 2$ & $\mathrm{CIOT} \rightarrow \mathrm{OP}$ & 0.139 & 0.478 & 3.442 & 0.000 & 0.201 & 0.255 & 0.736 & Supported \\
\hline H3 & $\mathrm{BIoT} \rightarrow \mathrm{SCP}$ & 0.137 & 0.347 & 2.539 & 0.006 & 0.105 & 0.118 & 0.584 & Supported \\
\hline $\mathrm{H} 4$ & CIoT $\rightarrow$ SCP & 0.139 & 0.465 & 3.338 & 0.000 & 0.189 & 0.246 & 0.702 & Supported \\
\hline H5 & $\mathrm{SCP} \rightarrow \mathrm{OP}$ & 0.154 & 0.481 & 3.115 & 0.001 & 0.277 & 0.238 & 0.754 & Supported \\
\hline
\end{tabular}

Note: $>$ t-value $=(\mathrm{p}$-value $):>2.58(* * * \mathrm{p}<0.01),>1.96(* * \mathrm{p}<0.05),>1.65(* \mathrm{p}<0.10)$

\subsubsection{Mediating effects}

In addition, two mediating effects are being tested to measure whether supply chain performance mediates the relationship between benefits and challenges of IoT adoption and organizational performance. Table 4.5 shows the result of the mediating effects. As mentioned before, SCP acts as a mediating variable in this study. The results show that the SCP mediates the relationship between CIOT and OP at t-value 2.687 and p-value 0.004 . Meanwhile, it shows significance statically at predicting SCP mediate the relationship between BIoT and OP at t-value 1.690 and p-value 0.046. Therefore, both hypotheses (i.e. H6, H7) are supported.

Table 5

Results of Mediating Effects

\begin{tabular}{|c|c|c|c|c|c|c|c|c|c|}
\hline \multirow{2}{*}{ Hypo-theses } & \multirow{2}{*}{ Path } & \multirow[t]{2}{*}{ Std Beta } & \multirow{2}{*}{ SE } & \multirow[t]{2}{*}{ t-value } & \multirow{2}{*}{ p-value } & \multirow[t]{2}{*}{$\mathbf{F}^{2}$} & \multicolumn{2}{|c|}{$\begin{array}{c}\text { Confidence } \\
\text { Interval }\end{array}$} & \multirow[t]{2}{*}{ Decision } \\
\hline & & & & & & & 0.05 & 0.95 & \\
\hline H6 & $\mathrm{BIoT} \rightarrow \mathrm{SCP} \rightarrow \mathrm{OP}$ & 0.099 & 0.167 & 1.690 & 0.046 & 0.043 & 0.210 & 0.380 & Supported \\
\hline $\mathrm{H} 7$ & $\mathrm{CIoT} \rightarrow \mathrm{SCP} \rightarrow \mathrm{OP}$ & 0.083 & 0.224 & 2.687 & 0.004 & 0.117 & 0.095 & 0.367 & Supported \\
\hline
\end{tabular}

Note: $>$ t-value $=(\mathrm{p}$-value $):>2.58(* * * \mathrm{p}<0.01),>1.96(* * \mathrm{p}<0.05),>1.65(* \mathrm{p}<0.10)$

\section{Discussion and conclusion}

The data analysis from this study has revealed that most manufacturing companies are not aware that the latest technology, such as IoT, can benefit their organizational performance. The results of the finding have supported six of seven hypotheses tested. The first research hypothesis predicts that the benefits of IoT adoption positively affects organizational performance. According to (Haddud et al., 2017), IoT has significant benefits to organizations where it can bring tangible business benefits in the operational process. The result of this study is not in line with the finding of (Haddud et al., 2017). It might be due to lacking comprehend information on the potential benefits of IoT adoption (Alshurideh et al., 2020; Lee \& Lee, 2015). The majority of the manufacturing companies in Malaysia realized the challenges rather than benefits of IoT adoption towards supply chain and organization performance. However, the manufacturing companies in Malaysia do agree that the benefits and challenges of IoT adoption positively affect the supply chain performance and further influence organizational 
performance. IoT can strengthen the supply chain by integrating objects by connecting them through the internet (Al Kurdi et al., 2021; Vass et al., 2018). According to Vass et al. (2018), for greater supply chain integration, IoT is required to close the gap between the physical and digital world by synchronizing all the flow of information with the physical flow. However, the company will face a challenge in data management as IoT sensors and devices generate massive amounts of data. If the company cannot invest in data storage, it will definitely cause a mess in the supply chain (Lee \& Lee, 2015; Mehmood et al., 2019). On the other hand, if the company can receive benefits of IoT adoption in the supply chain. (Alzoubi et al., 2020; Haddud et al., 2017) highlighted that IoT can improve product tracking and traceability, better inventory management and control and improved operational efficiency. Furthermore, the supply chain's ability to respond and adjust to the fast growth of IoT will achieve more significant benefits and more competitive advantages in the new business environment (Haddud et al., 2017; Joghee et al., 2021) . In conclusion, the manufacturing industry in Malaysia needs to be exposed more to the benefits of IoT rather than keep discussing its challenges. Knowing the benefits will make a huge difference in terms of performance. This study shows that supply chain performance mediates the benefits and challenges of IoT adoption and organizational performance. It means that adoption of IoT in the supply chain can have a positive effect on organizational performance. If the company has good management of supply chain and IoT adoption will improve organization performance and remain competitive in the market.

\section{Implications}

Research from this study contributes to the manufacturing industry in Malaysia and academics. In terms of theoretical value, this study also intends to fill up the research gap in the previous study. This study had carried out an analysis of the benefits and challenges of IoT adoption towards supply chain and organizational performance. This study can be one of the references for future researchers to better understand the effects of IoT on supply chain and organizational performance in the manufacturing industry. Besides, the manufacturing companies can use this study as their reference in deciding technology investment. It is believed that the result of this study can encourage manufacturing companies on IoT adoption in improving their supply chain and organizational performance.

\section{Limitations and recommendations}

The primary reference on population in this study is FMM directory. However, the details in the directory were not fully updated. Therefore, there are difficulties in reaching the targeted respondents, even with the frequent follow-up process, which led to a low response rate. As a recommendation for future study, the researchers can look at the specific effect of IoT adoption on supply chain and organizational performance. This is to get the idea of how the supply chain and the organizational performance can be further improved. There are pros and cons to all the inventions. The manufacturing companies can refer to the future study to invest in another technology as a supplement for IoT adoption.

\section{References}

Abdel-Basset, M., Manogaran, G., \& Mohamed, M. (2018). Internet of Things (IoT) and its impact on supply chain: A framework for building smart, secure and efficient systems. Future Generation Computer Systems, 86, 614-628. https://doi.org/10.1016/j.future.2018.04.051

Aburayya, A., Alshurideh, M., Al Marzouqi, A., Al Diabat, O., Alfarsi, A., Suson, R., Salloum, S. A., Alawadhi, D., \& Alzarouni, A. (2020). Critical success factors affecting the implementation of tqm in public hospitals: A case study in UAE Hospitals. Systematic Reviews in Pharmacy, 11(10). https://doi.org/10.31838/srp.2020.10.39

Al-Zu'bi, Z. M. F., Al-Lozi, M., Dahiyat, S. E., Alshurideh, M., \& Al Majali, A. (2012). Examining the effects of quality management practices on product variety. European Journal of Economics, Finance and Administrative Sciences, 51.

Al Kurdi, B., Alshurideh, M., \& Al afaishat, T. (2020). Employee retention and organizational performance: Evidence from banking industry. Management Science Letters, 10(16). https://doi.org/10.5267/j.msl.2020.7.011

Al Kurdi, B., Alshurideh, M., Nuseir, M., Aburayya, A., \& Salloum, S. A. (2021). The Effects of Subjective Norm on the Intention to Use Social Media Networks: An Exploratory Study Using PLS-SEM and Machine Learning Approach. In Advances in Intelligent Systems and Computing (Vol. 1339). https://doi.org/10.1007/978-3-030-69717-4_55

Alaali, N., Al Marzouqi, A., Albaqaeen, A., Dahabreh, F., Alshurideh, M., Mouzaek, E., Alrwashdh, S., Iyadeh, I., Salloum, S., \& Aburayya, A. (2021). The impact of adopting corporate governance strategic performance in the tourism sector: A case study in the Kingdom of Bahrain. Journal of Legal, Ethical and Regulatory Issues, 24(Special Issue 1).

Alhamad, A. Q. M., Akour, I., Alshurideh, M., Al-Hamad, A. Q., Kurdi, B. Al, \& Alzoubi, H. (2021). Predicting the intention to use google glass: A comparative approach using machine learning models and PLS-SEM. International Journal of Data and Network Science, 5(3), 311-320. https://doi.org/10.5267/j.ijdns.2021.6.002

Ali, N., Ahmed, A., Anum, L., Ghazal, T. M., Abbas, S., Khan, M. A., Alzoubi, H. M., \& Ahmad, M. (2021). Modelling supply chain information collaboration empowered with machine learning technique. Intelligent Automation and Soft Computing, 30(1), 243-257. https://doi.org/10.32604/iasc.2021.018983

Ali, N., M. Ghazal, T., Ahmed, A., Abbas, S., A. Khan, M., Alzoubi, H., Farooq, U., Ahmad, M., \& Adnan Khan, M. (2022). Fusion-Based Supply Chain Collaboration Using Machine Learning Techniques. Intelligent Automation \& Soft Computing, 31(3), 1671-1687. https://doi.org/10.32604/iasc.2022.019892 
Almaazmi, J., Alshurideh, M., Al Kurdi, B., \& Salloum, S. A. (2021). The Effect of Digital Transformation on Product Innovation: A Critical Review. In Advances in Intelligent Systems and Computing: Vol. 1261 AISC. https://doi.org/10.1007/978-3-030-58669-0_65

Alnuaimi, M., Alzoubi, H. M., Ajelat, D., \& Alzoubi, A. A. (2021). Towards intelligent organisations: An empirical investigation of learning orientation's role in technical innovation. International Journal of Innovation and Learning, 29(2), 207-221. https://doi.org/10.1504/IJIL.2021.112996

AlShamsi, M., Salloum, S. A., Alshurideh, M., \& Abdallah, S. (2021). Artificial intelligence and blockchain for transparency in governance. In Studies in Computational Intelligence (Vol. 912). https://doi.org/10.1007/978-3-030-51920-9_11

AlShehhi, H., Alshurideh, M., Kurdi, B. A., \& Salloum, S. A. (2021). The Impact of Ethical Leadership on Employees Performance: A Systematic Review. In Advances in Intelligent Systems and Computing: Vol. 1261 AISC. https://doi.org/10.1007/978-3-030-58669-0_38

Alshurideh, M., Salloum, S. A., Al Kurdi, B., \& Al-Emran, M. (2019). Factors affecting the social networks acceptance: An empirical study using PLS-SEM approach. PervasiveHealth: Pervasive Computing Technologies for Healthcare, Part F1479. https://doi.org/10.1145/3316615.3316720

Alshurideh, M. T., Al Kurdi, B., Masa'deh, R., \& Salloum, S. A. (2021). The moderation effect of gender on accepting electronic payment technology: a study on United Arab Emirates consumers. Review of International Business and Strategy, 31(3). https://doi.org/10.1108/RIBS-08-2020-0102

Alshurideh, Muhammad, Alsharari, N. M., \& Al Kurdi, B. (2019). Supply chain integration and customer relationship management in the airline logistics. Theoretical Economics Letters, 9(02), 392-414.

Alshurideh, Muhammad, Bataineh, A., Alkurdi, B., \& Alasmr, N. (2015). Factors Affect Mobile Phone Brand Choices Studying the Case of Jordan Universities Students. International Business Research, 8(3). https://doi.org/10.5539/ibr.v8n3p141

Alshurideh, Muhammad, Gasaymeh, A., Ahmed, G., Alzoubi, H., \& Kurd, B. Al. (2020). Loyalty program effectiveness: Theoretical reviews and practical proofs. Uncertain Supply Chain Management, 8(3), 599-612. https://doi.org/10.5267/j.uscm.2020.2.003

Alshurideh, Nicholson, \& Xiao. (2012). The effect of previous experience on mobile subscribers' repeat purchase behaviour. European Journal of Social Sciences, 30(3).

AlSuwaidi, S. R., Alshurideh, M., Al Kurdi, B., \& Aburayya, A. (2021). The Main Catalysts for Collaborative R\&D Projects in Dubai Industrial Sector. The International Conference on Artificial Intelligence and Computer Vision, $795-806$.

Alzoubi, H., \& Ahmed, G. (2019). Do TQM practices improve organisational success? A case study of electronics industry in the UAE. International Journal of Economics and Business Research, 17(4), 459-472. https://doi.org/10.1504/IJEBR.2019.099975

Alzoubi, H., Alshurideh, M., Kurdi, B. Al, \& Inairat, M. (2020). Do perceived service value, quality, price fairness and service recovery shape customer satisfaction and delight? A practical study in the service telecommunication context. Uncertain Supply Chain Management, 8(3), 579-588. https://doi.org/10.5267/j.uscm.2020.2.005

Alzoubi, H., Elrehail, H., Hanaysha, J., Al-Gasaymeh, A., \& Al-Adaileh, R. (2021). The Role of Supply Chain Integration and Agile Practices in Improving Lead Time During the COVID-19 Crisis. International Journal of Service Science, Management, Engineering, and Technology, 13(1), 1-11. https://doi.org/10.4018/ijssmet.290348

Alzoubi, H. M., \& Aziz, R. (2021). Does Emotional Intelligence Contribute to Quality of Strategic Decisions? The Mediating Role of Open Innovation. https://doi.org/10.3390/joitmc7020130

Alzoubi, H. M., Vij, M., Vij, A., \& Hanaysha, J. R. (2021). What leads guests to satisfaction and loyalty in UAE five-star hotels? AHP analysis to service quality dimensions. Enlightening Tourism, 11(1), 102-135. https://doi.org/10.33776/et.v11i1.5056

Alzoubi, H. M., \& Yanamandra, R. (2020). Investigating the mediating role of information sharing strategy on agile supply chain. Uncertain Supply Chain Management, 8(2), 273-284. https://doi.org/10.5267/j.uscm.2019.12.004

Anderson, Hair, Black, B. (2010). Multivariate data analysis 7th edition. Pearson Perntice Hall.

$\mathrm{Tu}$, M. (2018). An exploratory study of Internet of Things (IoT) adoption intention in logistics and supply chain management A mixed research approach. https://doi.org/10.1108/IJLM-11-2016-0274

Bagozzi, R. P. (2006). Evaluating Structural Equation Models with Unobservable Variables and Measurement Error: A Comment. Journal of Marketing Research, 18(3), 375. https://doi.org/10.2307/3150979

Caputo, A., Marzi, G., \& Pellegrini, M. M. (2016). The Internet of Things in manufacturing innovation processes: Development and application of a conceptual framework. Business Process Management Journal, $22(2), 383-402$. https://doi.org/10.1108/BPMJ-05-2015-0072

Garson, G.D. (2016). Partial Least Squares (PLS-SEM).

Gavrea, C., Stegerean, R., \& Ilies, L. (2011). Determinants of Organizational Performance: The Case of Romania. Challenges for the Knowledge Society, 6(2), 285-300.

Ghazal, T.M., Hasan, M. K., Alshurideh, M. T., Alzoubi, H. M., Ahmad, M., Akbar, S. S., Al Kurdi, B., \& Akour, I. A. (2021). IoT for smart cities: Machine learning approaches in smart healthcare-A review. Future Internet, 13(8). https://doi.org/10.3390/fi13080218

Ghazal, Taher M., Hasan, M. K., Alshurideh, M. T., Alzoubi, H. M., Ahmad, M., Akbar, S. S., Al Kurdi, B., \& Akour, I. A. (2021). IoT for Smart Cities: Machine Learning Approaches in Smart Healthcare-A Review. Future Internet, 13(8), 218. https://doi.org/10.3390/fi13080218 
Ghazal, Taher M, Alshurideh, M. T., \& Alzoubi, H. M. (2021). Blockchain-Enabled Internet of Things (IoT) Platforms for Pharmaceutical and Biomedical Research. The International Conference on Artificial Intelligence and Computer Vision, 589-600.

Haddud, A., Desouza, A., Khare, A., Lee, H., Desouza, A., \& Lee, H. (2017). Things integration in supply chains Examining potential benefits and challenges associated with the Internet of Things integration in supply chains. https://doi.org/10.1108/JMTM-05-2017-0094

Hair, J. F. J., Sarstedt, M., Hopkins, L., \& Kuppelwieser, V. G. (2014). Partial least squares structural equation modeling (PLS-SEM): An emerging tool in business research. European Business Review, 26(2), 106-121. https://doi.org/10.1108/EBR-10-2013-0128

Hair, J. F., Ringle, C. M., \& Sarstedt, M. (2011). PLS-SEM: Indeed a silver bullet. Journal of Marketing Theory and Practice, $19(2), 139-152$.

Hair Jr, J. F., Matthews, L. M., Matthews, R. L., \& Sarstedt, M. (2017). PLS-SEM or CB-SEM: updated guidelines on which method to use. International Journal of Multivariate Data Analysis, 1(2), 107-123.

Hamadneh, S., Pedersen, O., Alshurideh, M., Kurdi, B. Al, \& Alzoubi, H. (2021). An Investigation Of The Role Of Supply Chain Visibility Into The Scottish Blood Supply Chain. Journal of Legal, Ethical and Regulatory Issues, 24(Special Issue 1), 1-12.

Hanaysha, J., Al-Shaikh, M., \& Alzoubi, H. (2021). Importance of Marketing Mix Elements in Determining Consumer Purchase Decision in the Retail Market. International Journal of Service Science, Management, Engineering, and Technology, 12(6), 56-72.

Hanaysha, J. R., Al-Shaikh, M. E., Joghee, S., \& Alzoubi, H. (2021). Impact of Innovation Capabilities on Business Sustainability in Small and Medium Enterprises. FIIB Business Review, 1-12. https://doi.org/10.1177/23197145211042232

Hasselblatt, M., Huikkola, T., Kohtamäki, M., Nickell, D., Hasselblatt, M., Huikkola, T., Kohtamäki, M., \& Nickell, D. (2018). Modeling manufacturer 's capabilities for the Internet of Things. https://doi.org/10.1108/JBIM-11-2015-0225

Hayajneh, N., Suifan, T., Obeidat, B., Abuhashesh, M., Alshurideh, M., \& Masa'deh, R. (2021). The relationship between organizational changes and job satisfaction through the mediating role of job stress in the Jordanian telecommunication sector. Management Science Letters, 11(1), 315-326.

Henseler, J, Ringle, C. M., \& Sarstedt, M. (2015). A new criterion for assessing discriminant validity in variance-based structural equation modeling. Journal of the Academy of Marketing Science2, 43(1), 115 - 135.

Henseler, Jörg, Ringle, C., \& Sarstedt, M. (2012). Using Partial Least Squares Path Modeling in International Advertising Research: Basic Concepts and Recent Issues. In Handbook of Research on International Advertising (pp. 252-276). https://doi.org/10.4337/9781848448582.00023

Joghee, S., Kurdi, B. Al, Alshurideh, M., Alzoubi, H., Vij, A., Muthusamy, M., \& Hamadneh, S. (2021). Expats Impulse Buying Behaviour in Uae: a. 24(1), 1-24.

Kaliani Sundram, V. P., Chandran, V. G. R., \& Awais Bhatti, M. (2016). Supply chain practices and performance: the indirect effects of supply chain integration. Benchmarking. https://doi.org/10.1108/BIJ-03-2015-0023

Krotov, V., Bauernfeind, A. J., \& Building, B. (2017). The Internet of Things and new business opportunities. Business Horizons, 60(6), 831-841. https://doi.org/10.1016/j.bushor.2017.07.009

Kurdi, Barween Al, Alshurideh, M., \& Alnaser, A. (2020). The impact of employee satisfaction on customer satisfaction: Theoretical and empirical underpinning. Management Science Letters, 10(15). https://doi.org/10.5267/j.msl.2020.6.038

Kurdi, Barween Al, Elrehail, H., Alzoubi, H. M., Alshurideh, M., \& Al-adaileh, R. (2021). THE INTERPLAY AMONG HRM PRACTICES, JOB SATISFACTION AND INTENTION TO LEAVE: AN EMPIRICAL INVESTIGATION. 24(1), 1-14.

Lee, I., \& Lee, K. (2015). The Internet of Things (IoT): Applications, investments, and challenges for enterprises. Business Horizons, 58(4), 431-440. https://doi.org/10.1016/j.bushor.2015.03.008

Loeb, S., Dynarski, S., Mcfarland, D., Morris, P., Reardon, S., \& Reber, S. (2017). Descriptive analysis in education: A guide for researchers The National Center for Education Evaluation and Regional Assistance (NCEE) conducts unbiased largescale evaluations of education programs and practices. March.

Lowry, P. B., \& Gaskin, J. (2014). Partial least squares (PLS) structural equation modeling (SEM) for building and testing behavioral causal theory: When to choose it and how to use it. IEEE Transactions on Professional Communication, 57(2), 123-146. https://doi.org/10.1109/TPC.2014.2312452

Mehmood, T., Alzoubi, H. M., Alshurideh, M., Al-Gasaymeh, A., \& Ahmed, G. (2019). Schumpeterian entrepreneurship theory: Evolution and relevance. Academy of Entrepreneurship Journal, 25(4), 1-10.

Mehrez, A. A. A., Alshurideh, M., Kurdi, B. A., \& Salloum, S. A. (2021). Internal Factors Affect Knowledge Management and Firm Performance: A Systematic Review. In Advances in Intelligent Systems and Computing: Vol. 1261 AISC. https://doi.org/10.1007/978-3-030-58669-0_57

Nuseir, M. T., Aljumah, A., \& Alshurideh, M. T. (2021). How the Business Intelligence in the New Startup Performance in UAE During COVID-19: The Mediating Role of Innovativeness. In Studies in Systems, Decision and Control (Vol. 334). https://doi.org/10.1007/978-3-030-67151-8_4

Okano, M. T. (2017). IOT and Industry 4.0: The Industrial New Revolution. ICMIS-17 - International Conference on Management and Information Systems, September, 75-82.

Olli Lehtisalo. (2018). The Application of Digital Technologies in Supply Chain Management Master 's thesis 2018.

Rajgopal, J. (2016). Supply Chains: Definitions \& Basic Concepts. University of Pittsburgh, 32. 
Richard, P. J., Devinney, T. M., Yip, G. S., \& Johnson, G. (2009). Measuring organizational performance: Towards methodological best practice. Journal of Management, 35(3), 718-804. https://doi.org/10.1177/0149206308330560

Shamout, M., Ben-Abdallah, B., Alshurideh, M., Alzoubi, H., Al Kurdi, B., and Hamadneh, S. (2022). A conceptual model for the adoption of autonomous robots in supply chain and logistics industry. Uncertain Supply Chain Management, 10, $1-16$.

Showkat, N., \& Parveen, H. (2017). Quadrant-I (e-Text). August, 0-9.

Sillanpää, I. (2010). Supply chain performance measurement in the manufacturing industry A single case study research to develop a supply chain performance measurement framework. UNIVERSITY OF OULU.

Tadejko, P. (2015). Application of Internet of Things in Logistics - Current Challenges. Economics and Management, 7(4), 54-64. https://doi.org/10.12846/j.em.2015.04.07

Tang, C., Huang, T. C., \& Wang, S. (2018). Telematics and Informatics The impact of Internet of things implementation on fi rm performance. Telematics and Informatics, 35(7), 2038-2053. https://doi.org/10.1016/j.tele.2018.07.007

Tjahjono, B. (2017). ScienceDirect ScienceDirect ScienceDirect ScienceDirect What does Industry 4 . 0 mean to Supply Chain? What does Society to Supply Costing models for capacity optimization in Industry 4 . 0 : Trade-off between used capacity and operational efficiency. Procedia Manufacturing, 13, 1175-1182. https://doi.org/10.1016/j.promfg.2017.09.191

Vass, T. De. (2018). The effect of "Internet of Things " on supply chain integration and performance: An organisational capability perspective. 22, 1-29.

Vass, T., Shee, H., \& Miah, S. (2018). The effect of "Internet of Things" on supply chain integration and performance: An organisational capability perspective. Australasian Journal of Information Systems, 22, 1-29. https://doi.org/10.3127/ajis.v22i0.1734

Yang, H., Kumara, S., Bukkapatnam, S. T. S., \& Tsung, F. (2019). The Internet of Things for Smart Manufacturing: A Review. IISE Transactions, January, 1-35. https://doi.org/10.1080/24725854.2018.1555383

Zhou, L., Chong, A. Y. L., \& Ngai, E. W. T. (2015). Supply chain management in the era of the internet of things. International Journal of Production Economics, 159, 1-3. https://doi.org/10.1016/j.ijpe.2014.11.014

\section{Appendix A}

List of measurement items

\begin{tabular}{|c|c|c|}
\hline Item & Questions & Sources \\
\hline \multicolumn{3}{|c|}{ Benefits of IoT Adoption } \\
\hline & Supply chain efficiency & \multirow{23}{*}{$\begin{array}{l}\text { (Haddud et } \\
\text { al., 2017; } \\
\text { Vass et al., } \\
\text { 2018; Zhou } \\
\text { et al., } \\
20115 \text { ) }\end{array}$} \\
\hline & We have been able to identify the supply chain efficiency to ... & \\
\hline B1 & Better control and management of inventories. & \\
\hline B2 & Development of operational efficiency. & \\
\hline B3 & Improved fleet and transportation management. & \\
\hline B4 & Better predictive maintenance of assets. & \\
\hline B5 & Production adjustments based on real-time information of the demand and capacity availability. & \\
\hline B6 & Better proactive replenishment of material. & \\
\hline B7 & Improvement in company assets utilization, reduction in machinery loss and downtimes. & \\
\hline B8 & Improvement in just-in-time manufacturing through better production scheduling. & \\
\hline \multirow[t]{3}{*}{ B9 } & Reduction of Bullwhip effect within supply chain. & \\
\hline & Visibility of supply chain & \\
\hline & We have been able to identify the visibility of supply chain to ... & \\
\hline B10 & More transparency and visibility of information and material flows. & \\
\hline B11 & Improved products tracking and traceability. & \\
\hline B12 & Improved integration of internal business processes. & \\
\hline B13 & Better support to e-commerce platforms through reliability and availability in information. & \\
\hline B14 & Insights from customer patterns and behavior. & \\
\hline B15 & Prediction of optimal level of production by reducing overproduction and underproduction. & \\
\hline B16 & Facilitate product development and commercialization. & \\
\hline B17 & Better integration along inter-organizational business processes. & \\
\hline B18 & Transparency from local and international logistics operations. & \\
\hline B19 & Enhancement the real-time visibility of demand and capacity fluctuations. & \\
\hline \multicolumn{3}{|c|}{ Challenges of IoT Adoption } \\
\hline & Technology trustworthiness & \multirow{8}{*}{$\begin{array}{l}\text { (Haddud et } \\
\text { al., 2017; } \\
\text { Vass et al., } \\
2018 \text { ) }\end{array}$} \\
\hline & We have been able to identify the trustworthiness of technology to ... & \\
\hline $\mathrm{C} 1$ & Device and network security risks and vulnerabilities. & \\
\hline $\mathrm{C} 2$ & $\begin{array}{l}\text { Services platforms of storage to accommodate large volume of data with high levels of security and } \\
\text { reliability. }\end{array}$ & \\
\hline $\mathrm{C} 3$ & $\begin{array}{l}\text { Platforms to manage and control huge volume of data, velocity of processing, validation, and diversity of } \\
\text { information. }\end{array}$ & \\
\hline $\mathrm{C} 4$ & Effective integration and synchronization of data and cloud computing systems. & \\
\hline $\mathrm{C} 5$ & Services and technological products still not mature. & \\
\hline C6 & Solutions for communication and signal coverage to attend different modes of transport and products. & \\
\hline
\end{tabular}


C7 Seamless integration of business processes, information and communication technologies in cyberspace.

Organization adjustment

We have been able to identify organization adjustment to ...

C8 Challenges in obtaining the needed supporting staff with right skills and knowledge.

C9 Technical and technological integration.

C10 Employees' resistance to new technologies and practices.

C11 Compatibility among sensors, networks, and applications from different technology and vendors.

C12 Availability of financial resources to support implementation and maintenance.

C13 Applications coding development.

C14 Integration along multiples supply chains with heterogeneous technologies and data services.

C15 Global standard of IoT communication protocol for smart objects and systems.

C16 Financial investments from all participants to design and deploy IoT technologies and solutions.

C17 Design of new SC business models to support the still unstructured firm oriented ecosystems.

Organizational Performance

\section{Financial}

We been able to develop our organizational operations to ...

OP1 Improve productivity (e.g. assets, operating costs, labor costs).

OP2 Improve sales of existing products.

OP3 Find new revenue streams.

OP4 Improve financial ratio such as return on investment return on asset return on equity.

OP5 Save cost during production process in raw material, energy, water, human, machine, and equipment.

OP6 Reduce the cash-to-cash cycle time.

Non - Financial

We been able to develop our organizational operations to ...

OP7 Improve return/re-use/recycle.

OP8 Reduce energy use.

OP9 Build strong and continuous bonds with customers.

OP10 Gain precise knowledge of customer buying patterns.

OP11 Improve customer satisfaction.

OP12 Improve employee satisfaction.

OP13 Improve employee health and safety.

\section{Supply Chain Performance}

Supply Chain Flexibility

We have been able to develop our supply chain processes to ...

(Haddud et

al., 2017;

Vass et al.,

SCP1 Improve supply chain flexibility (react to product changes, volume, and mix).
SCP2

(Kaliani

Sundram et

SCP3

Ability to respond to and accommodate the periods of poor manufacturing performance such as machine
breakdown.

al., 2016)

SCP4 Ability to respond to and accommodate the periods of poor supplier performance.

SCP5 Ability to respond to and accommodate the periods of poor delivery performance.

SCP6 Ability to respond to and accommodate new products, new markets or new competitors.

Supply Chain Resource

We been able to develop our organizational operations to ...

SCP7 Improve value-added productivity per employee.

SCP8 Total cost of resources used

SCP9 Total cost of distribution, including transportation and handling cost

SCP10 Total cost of manufacturing, including labor, maintenance and re-work cost

SCP11 Cost associated with held inventory

SCP12 Return on investment

Supply Chain Output

Based on the most recent three years performance, our company has ...

SCP13 Improve product quality.

SCP14 Improve supply chain delivery reliability.

SCP15 Sales

SCP16 Order fill rate

SCP17 On time deliveries

SCP18 Improve perfect order fulfilment (deliveries with no errors).

SCP19 Customer response time.

SCP20 Manufacturing lead time.

SCP21 Customer complaints.


(C) 2022 by the authors; licensee Growing Science, Canada. This is an open access article distributed under the terms and conditions of the Creative Commons Attribution (CCBY) license (http://creativecommons.org/licenses/by/4.0/). 